\title{
AS MULHERES BRASILEIRAS NA DITADURA CIVIL-MILITAR: AVANÇOS E ABORDAGENS EM QUASE QUATRO DÉCADAS DE RESISTÊNCIA
}

\author{
Ary Albuquerque Cavalcanti Junior ${ }^{1}$
}

RESUMO: O presente artigo pretende fazer uma breve abordagem dos estudos em torno das mulheres brasileiras na resistência à ditadura civil-militar nos últimos anos. Passados vinte e sete anos da publicação do primeiro estudo acadêmico sobre o tema com Marcelo Ridenti (1990), percebe-se o quanto este tema de pesquisa passou a se desenvolver no Brasil, tendo inúmeras universidades suscitado debates, estudos e até livros sobre a temática. Dessa forma, ao realizar tal abordagem, destacamos as contribuições não apenas da academia, mas da literatura, de obras memorialisticas e autobiográficas que apresentam as ações das mulheres no período e suas diferentes formas de resistência.

PALAVRAS-CHAVE: Ditadura; Mulheres; Resistência.

\section{BRAZILIAN WOMEN IN THE CIVIL-MILITARY DICTATORSHIP: ADVANCES AND APPROACHES IN NEXT FOUR DECADES OF RESISTANCE}

\begin{abstract}
This article intends to make a brief approach to the studies about Brazilian women in resistance to civil-military dictatorship in recent years. Twentyseven years after the publication of the first academic study on the subject with Marcelo Ridenti (1990), one can see how much this research theme has developed in Brazil, with numerous universities raising debates, studies and even books on the subject. Thus, in carrying out such an approach, we highlight the contributions not only of the academy, but of literature, of memorialistic and autobiographical works that present the actions of women in the period and their different forms of resistance.
\end{abstract}

KEYWORDS: Dictatorship; Woman; Resistance.

\section{LAS MUJERES BRASILEÑAS EN LA DITADURA CIVIL-MILITAR: AVANCES Y ENFOQUES EN PRACTICAMENTE CUATRO DÉCADAS DE RESISTENCIA}

RESUMEN: El presente artículo pretende hacer un breve enfoque de los estudios en torno a las mujeres brasileñas en la resistencia a la dictadura civil-militar en los últimos años. En los últimos veinte y siete años de la publicación del primer estudio académico sobre el tema con Marcelo Ridenti (1990), se percibe cuánto este tema de investigación

\footnotetext{
${ }^{1}$ Doutorando em História pela Universidade Federal da Grande Dourados (UFGD). Mestre em História Regional e Local pela Universidade do Estado da Bahia (UNEB).
}

Fronteiras: Revista de História | Dourados, MS |v. 20 | n. 36 |p. 177-199| Jul. / Dez. 2018 
pasó a desarrollarse en Brasil, teniendo innumerables universidades que suscitaran debates, estudios e incluso libros sobre la temática. De esta forma, al realizar tal abordaje, destacamos las contribuciones no sólo de la academia, sino de la literatura, de obras memorialisticas y autobiográficas que presentan las acciones de las mujeres en el período y sus diferentes formas de resistencia.

PALABRAS CLAVE: Dictadura; las mujeres; Resistencia.

\section{ELEMENTOS NORTEADORES}

Nas últimas décadas, inúmeros objetos e temas passaram a ser discutidos pelos historiadores e com eles a recuperação ou a inovação de discussões até então pouco debatidas. Nessa perspectiva, a história das mulheres, passou a receber olhares cada vez mais atenciosos em determinados espaços e tempos, logo, neste artigo, serão apresentados trabalhos que as referenciam na resistência à ditadura civil-militar iniciada em 1964.

Como elemento norteador inicial, inseridas num contexto rodeado de princípios morais e éticos, alicerçados em uma cultura cristã, por muito tempo a função das mulheres, como difundida, era cuidar do privado (casa), enquanto a dos homens, do público (política). Assim, os discursos que predominavam no século passado, buscavam moralizar, e ao mesmo tempo comandar o comportamento de cada indivíduo, trazendo em si uma misoginia de clara oposição entre homens e mulheres (COLLING, 1997).

No que se refere ao período ditatorial brasileiro, que se estendeu entre 1964 e 1985, apesar da ampla presença das mulheres na resistência, é importante destacar que nem todas as mulheres estiveram envolvidas na luta contra a ditadura, algumas por uma questão ideológica dentre outros fatores se posicionaram a favor, como exemplo, citamos a ampla participação nas Marchas com Deus pela família e pela liberdade, além de outras que não se posicionaram ou que não tinham conhecimento sobre a política brasileira, como destaca Ediane Santana (2009):

Ou seja, a multiplicidade do movimento de mulheres pode abarcar, sem contradições, movimentos feministas e que possuem uma visão crítica quanto aos lugares sociais de gênero, mas também pode conter mobilizações como as Marchas da família que, apesar de arregimentar um amplo número de mulheres, foi organizado com base na 
manutenção das mulheres na condição de mães, donas de casa e esposas exemplares, bem como buscou preservar o lugar social a elas destinado: a família (SANTANA, 2009 p. 28).

Dessa forma, destaca-se que neste artigo, se discutirá apenas obras e pesquisas que têm como tema a resistência de mulheres à ditadura militar em diferentes frentes, debruçando-se nas contribuições que tais trabalhos suscitaram para debates atuais. Assim, metodologicamente, foi realizado um levantamento bibliográfico que inclui desde obras memorialísticas à literatura no intuito de fazer um levantamento amplo e conciso de tais aportes, os quais serão apresentados ao longo do trabalho.

\section{DAS OBRAS MEMORIALÍSTICAS AS AUTOBIOGRÁFICAS}

No âmbito da produção memorialística de mulheres na resistência à ditadura, foi realizado um levantamento bibliográfico com o objetivo de perceber a produção dessa memória escrita por quem vivenciou o período ou está/esteve presente em coprodução. Assim, ainda que reconhecendo a vasta produção memorialística da época, o que durante muito tempo se destacou foram às obras referentes ao militante homem. Como destaca Margareth Rago (2013):

Na verdade, depois do fim da ditadura militar no Brasil, as memórias, testemunhos, as autobiografias ou os romances memorialistas que tratam da experiência da militância política em partidos de esquerda e da prisão foram, em sua maior parte, produzidos por militantes do sexo masculino, embora muitas mulheres tivessem tido uma atuação de destaque nos grupos políticos "revolucionários" e na resistência contra o regime (RAGO, 2013, p.62).

A partir do que expõe a autora anteriormente citada, chegou-se a percepção de que as mulheres ainda possuem poucas obras por elas ou sobre elas na resistência à ditadura em comparação às que têm homens como militantes. Sendo assim, deve-se problematizar, a falta de trabalhos se deve a pouca divulgação ou ausência de tais produções? Eis o questionamento central deste artigo e que será respondido no seu decorrer.

Como principais obras encontradas, destacam-se Memórias do exílio- 1964-19?? de Celso Cavalcanti e Jovelino Ramos (1980), Memórias das mulheres do exílio 
produzida por Albertina Costa, Maria Moraes, Norma Marzola e Valentina Rocha (1980) e Glória, Mãe de preso politico de Gilney Viana (2000). Salienta-se que tais, não excluem ou encerram a possibilidade de existirem outras produções memorialísticas, bem como autobiográficas, o qual se espera encontrá-las brevemente em outros estudos de mesmo cunho, haja vista a seletividade do historiador com suas fontes e a produção crescente das últimas décadas.

Quanto à primeira obra destacada, Memórias do exílio- 1964-19?? (1980)², de Pedro Celso Cavalcanti e Jovelino Ramos, foi escrita ainda no período ditatorial, mas precisamente no momento das discussões sobre abertura política e um ano após a assinatura da Lei de Anistia em agosto de 1979. Segundo os autores, o livro surgiu a partir de suas experiências de exílio na Polônia, enquanto eram perseguidos políticos. Logo, preocupados com o passado e sua construção para as novas gerações, como mencionam, realizaram a união de nove depoimentos e onze manuscritos de homens e mulheres (quatro), retratando o período ditatorial a partir de suas vivências de resistência política no Brasil e no exílio.

Como afirmam Cavalcanti e Ramos (1980), uma das maiores dificuldades foi a instabilidade politica do período, potencializando os medos e receios que rondavam os exilados políticos e seus possíveis retornos ao Brasil. Assim, para explicar o número de apenas quatro mulheres, destacam que muitas mulheres preferiram o anonimato, não só pelo medo já mencionado, mas pela exposição que sofreram na ditadura e que sofreriam com a exposição de suas memórias.

As mulheres apresentadas na obra são Anina de Carvalho, Juliana Rocha, Marijane Lisboa e Maria Auxiliadora Lara Barcellos, as quais deixam claras as questões relacionadas à negação do ideário doméstico e a elevação da representatividade política das mulheres, buscando descontruir, a partir do discurso o modelo de presença feminina apenas no âmbito privado. Além disso, deixam perceptível a noção de estarem fazendo

\footnotetext{
2 "Memórias do exílio" foi um projeto cujo objetivo era reunir o máximo de memórias de exilados brasileiros no intuito de denunciar as práticas militares, a vida no exílio e produzir um material para o presente. O projeto começou em 1974 a partir dos convites a 1.500 exilados espalhados pelo mundo até sua publicação em 1980. Este projeto deu origem às obras "Memórias do Exílio" e "Memórias de mulheres no exílio" patrocinadas por Paulo Freire, Abdias do Nascimento e Nelson Werneck Sodré, cujo objetivo era deixar um material para o presente.
}

Fronteiras: Revista de História | Dourados, MS |v. 20 | n. 36 |p. 177-199| Jul. / Dez. 2018 
parte de uma geração consciente politicamente de seus atos e do projeto que desejavam para o país, aproximando-se de uma memória coletiva (HALBWACHS, 1990).

Assim, dotados de grande ideário politico e defensores de uma esquerda antiburguesia, Cavalcanti e Ramos (1980) tecem uma grande contribuição para estudos memorialísticos dos anos de ditadura no Brasil. Com riquíssimos relatos, repletos de detalhes dos viventes e emoções transmitidas em palavras, a obra é bem definida em sua proposta de denunciar e rememorar os fatos a partir da ótica do militante. No que concerne a participação das mulheres, as apresentadas permitem uma análise importante não apenas memorialística, mas de gênero e luta política, os quais são de suma importância para a construção que tecem de si, bem como seus relatos podem ser observados enquanto fontes riquíssimas para outras pesquisas.

No mesmo princípio da obra anterior, Albertina Costa, Valentina Lima, Maria Moraes e Norma Marzola (1980) dão segmento ao projeto Memórias do exílio, lançando Memórias das mulheres do exílio, sendo a primeira obra memorialística com relatos apenas de mulheres sobre o período. Com quarenta e seis depoimentos, estes destacam desde situações vividas em solo brasileiro ao exílio vivenciado pelas mulheres.

Segundo Costa (1980) a construção da obra se deu a partir do encontro de um grupo de mulheres do projeto "Memórias do exílio" em Lisboa, Portugal ${ }^{1}$. Dessa forma, trazendo um ponto de vista das mulheres no exílio, as autoras apresentam muitos debates em torno de uma cultura da época e principalmente uma reflexão em torno da memória do período. Segundo elas, como principal razão para a realização da obra foi buscar a "vivência como mulheres no terreno onde o subjetivo e o objetivo se entrelaçam: o das emoções e o da história pessoal concreta, das mudanças cotidianas e nem por isso menores, nem por isso menos históricas" (COSTA, 1980, p. 17). Assim, não apenas como denúncia, mas, antes de mais nada pode-se observar tal obra como um manifesto de militância contínua em torno da presença feminina no âmbito da política e da história, algo perceptível no trecho destacado.

Uma crítica importante realizada pelas autoras se reporta a historiografia, as quais destacam o pouco espaço dado às mulheres, algo que só suscitará discussões dentro da teoria da historia partir de década de 90, ou seja, dez anos após seu lançamento. Assim, traçando um perfil das mulheres que estiveram exiladas em 
As mulheres brasileiras na ditadura civil-militar: avanços e abordagens em quase quatro décadas de resistência Ary Albuquerque Cavalcanti Junior

diversos países durante o período militar, as autoras, dotadas de uma linguagem politizada, mesclam histórias de vida em meio a decisões que precisaram ser tomadas durante a militância, o exílio e as saudades que sentiam do Brasil.

A partir de reflexões importantes para compreendermos a memória do período, a partir das mulheres apresentadas, tendo o exílio como plano de fundo, a obra de Costa ainda que passível de problematizações em torno da reconstrução memorialística apresenta um material riquíssimo para análises posteriores. Logo, percebemos que a função das memórias apresentadas é passar aos leitores as lutas diárias e o quanto a ditadura privou essas e tantas outras mulheres de viverem uma vida em seu país.

No que concerne a obra, Gloria, Mãe de preso político de Gilney Amorim Viana (2000), observa-se uma abordagem distinta das até então apresentadas. O referido autor, preso político durante o período remonta as experiências de sua mãe, Maria da Glória Amorim Viana, constituindo uma espécie de homenagem à sua trajetória de mãe aguerrida. Apesar de única, a história de Maria da Glória ${ }^{3}$ simboliza as agruras compartilhadas por tantas outras mães de presos políticos.

Dividindo a obra em capítulos, Viana (2000) busca abordar a vida de Maria da Glória a partir da formação de sua consciência social e política em diferentes fases da vida. Em inúmeras passagens é possível perceber como as questões de moralidade e a cultura de época influenciavam as ações femininas, algo já apontado por autores aqui citados como sendo fatores condicionantes no convívio social das mulheres. De acordo com a narrativa do livro, até a prisão do filho, Maria da Glória não manifestava nenhum interesse em se envolver com política, mesmo quando se casou e seu companheiro se tornou prefeito. Contudo, com a situação do filho, o interesse pela política surgiu quase como uma necessidade, remetendo ao sentimento materno de proteção.

Quando eu soube da prisão de Gilney, fiquei traumatizada. Inicialmente, não sabia o que pensar, depois veio um sentimento que eu não consegui entender, e quando entendi custou-me muito sofrimento para aceitar: eu era uma mãe de preso político (VIANA, 2000, p. 53).

\footnotetext{
${ }^{3}$ Maria da Glória Amorim Viana, baiana, nascida em Jacobina, parte para Minas Gerais com seu marido e filhos em busca de melhores condições de vida e após a efervescência politica da década de 70 se vê com o título de "mãe de preso político", após seu filho Gilney Amorim Viana ser preso político no estado de Minas Gerais.
} 
Se dedicando a defender o filho, Glória percebeu que vivia sob um Estado de exceção, no qual os direitos estavam cerceados. Essa mudança de entendimento aflorou ainda mais com suas visitas à penitenciária de Neves, em Belo Horizonte, onde passou a ouvir relatos de outros familiares de presos políticos. Segundo Maria da Glória,

Meu filho procurava nos passar segurança e tranquilidade. Queria que não me preocupasse e que não intercedesse junto aos militares; e se o fizesse, que fosse por conta própria.

Mas eu pensava diferente: vou procurar Fidelcino (irmão do Divaldo e enfronhado com Magalhães Pinto); vou procurar o coronel não sei das quantas; vou tirar o meu filho da cadeia (VIANA, 2000, p. 53).

Destaca-se que a reconstrução da vida de Maria da Glória realizada por Viana, fortalece a importância da contribuição de mães brasileiras na resistência à ditadura, onde quebravam a barreira da incomunicabilidade e chamavam a atenção para o arbítrio e lutavam pela liberdade e/ou anistia de seus filhos.

Ao analisar a obra de Viana é importante mencionar a relação constante entre o ser filho e o "ser" autor, onde a subjetividade de filho é transparente a cada página. Contudo, por não se tratar de uma obra acadêmica, o que não quer dizer que não sejam também subjetivas, ou por não haver essa pretensão, sua liberdade poética, bem como sua carga emocional são importantes na observação de como reelabora a história de sua mãe. Logo, entre a reconstrução da vida de sua mãe, há sua própria história de vida, uma vez que a mesma só foi mãe de preso político devido a sua militância, traz reflexões importantes, bem como ressignificações para a ditadura.

\section{OBRAS ACADÊMICAS DÉCADA DE 90}

No que concerne à academia brasileira, durante anos as mulheres estiveram fora do contexto de luta política na ditadura militar (RIDENTI, 1993). Somando-se a isto, inúmeros receios de uma abertura recente de documentos, bem como os traumas de vivencias que foram submetidas, contribuíram para que muitas não quisessem falar sobre suas vivências. No entanto, será na década de 90 que surgirão as primeiras obras e debates sobre a ditadura civil-militar e consequentemente da participação e resistência das mulheres. 
A partir de uma classificação cronológica das publicações, o primeiro a debater a presença da mulher na resistência à ditadura foi o cientista social Marcelo Ridenti em 1990, com seu trabalho "As mulheres na política brasileira: os anos de chumbo" e posteriormente em "O fantasma da revolução brasileira" (1993) quando destaca um subcapítulo para discutir a temática.

Consistindo em um artigo, em "As mulheres na política brasileira: os anos de chumbo" Ridenti destaca a participação das mulheres na política entre as décadas de 1960 e 70, dando enfoque principal à luta armada. Ainda neste trabalho são apresentados os movimentos de esquerda e de luta armada no país, os quais segundo o autor, "esses contaram com a participação de várias mulheres, principalmente jovens intelectualizadas, ainda que em número muito inferior à participação masculina", demonstrando até então os embates que a participação das mulheres teria na história recente do país.

Posteriormente, Ridenti (1993) desenvolveu um grande debate acerca da esquerda brasileira e suas heterogeneidades a partir da luta armada. Em sua obra "O fantasma da revolução brasileira" o autor não se dispõe exclusivamente às mulheres, pois, tenta explicar como a esquerda fracassou em seu plano de revolucionário. Para tanto, destina algumas páginas do subtítulo "Obscuros heróis, sem vez e sem voz" no qual traça algumas reflexões importantes sobre a presença das mulheres na esquerda, além de utilizar uma série de documentos para comprovar que muitas mulheres tiveram participação nos anos ditatoriais.

Segundo informações colhidas pelo banco de dados do Brasil Nunca Mais, apresentadas por Ridenti (1993), entre os anos de 1960 e 1970, 16\% dos processos eram destinados às mulheres, tendo respectivamente a AP (Ação Popular), a ALN (Ação Libertadora Nacional), o PC do B (Partido Comunista do Brasil), a VAR (Vanguarda Revolucionária), o PCBR (Partido Comunista Brasileiro Revolucionário) e o POC (Partido Operário Cristão) os maiores índices de presença feminina. Quanto à ocupação das mulheres, Ridenti (1993) destaca que estas eram em sua maioria estudantes $(32,2 \%)$ e professoras (23,0\%), tendo, ainda trabalhadoras de nível médio (19,2\%), com formação superior $(17,9 \%)$ trabalhadoras doméstica $(6,1 \%)$ e as que exerciam outras funções $(1,6 \%)$. A partir de tais dados, observamos o quanto às mulheres vinham de 
espaços sociais e políticos distintos, algo que é perceptível observar em obras mais específicas, as quais algumas serão aqui retratadas.

Em sua obra Ridenti ainda critica os partidos de esquerda, nos quais as mulheres tiveram pouca posição de "destaque" ou liderança, algo aqui relativizado por nós, haja vista que a pesquisa foi desenvolvida em 1993 e posteriormente a este, muitos trabalhos mostraram muitas mulheres a frente de cargos importantes. Dessa forma, apesar de direcionar algumas páginas para discutir a presença das mulheres na ditadura, o referido autor permite observar o quão era tímido o debate sobre tal presença na academia do final do século XX.

Partindo da antropologia, em 1996, Elizabeth Ferreira lançou a obra Mulheres, militância e memória, se tornando a primeira obra publicada, de cunho acadêmico, cujo objeto era exclusivamente a mulher na ditadura civil-militar brasileira. Segundo a autora:

[...] a reconstituição da trajetória coletiva desse grupo de mulheres e de suas trajetórias individuais, num processo de constante interação dessas duas instâncias, constrói uma outra versão desse período da história brasileira, ao mesmo tempo que as faz emergir pela primeira vez como agentes, já que, até então, tinham estado sistematicamente ausentes dos registros históricos (FERREIRA, 1996, p. 15).

Perfazendo um excelente trabalho, Ferreira, faz inúmeras reflexões em torno da das discussões de gênero e sobre as mulheres no período, para isso, apresenta treze entrevistas com mulheres que enfrentaram a repressão e o autoritarismo em diferentes momentos e estados da região Sul-Sudeste do Brasil. Trabalhando na perspectiva de mulheres guerrilheiras, seu trabalho tem uma enorme significância para os estudos posteriores, sendo apontado como um dos clássicos sobre o tema devido as inovações teórico metodológica que apresenta.

No que se relaciona as discussões de gênero e do espaço atribuído às mulheres, Ferreira (1996) afirma que "a diferenciação entre os sexos está na base do processo classificatório que organiza a sociedade, ao mesmo tempo que é, ela própria, construída pela cultura" (FERREIRA, 1996, p. 51). Esta colocação da autora acaba por problematizar as relações pessoais dentro dos movimentos de esquerda, onde a participação entre homens e mulheres era diferenciada e desigual, algo já observado por 
Ridenti. Ciente da complexidade do tema Ferreira (1996) tem o cuidado de situar as mulheres em seu tempo e fazer as devidas problematizações, levando em consideração as diferentes gerações e abordagens quanto ao grupo que estava inserida.

Ainda durante a década de 90, precisamente em 1997, a historiadora Ana Maria Colling publicou, "A resistência da mulher à ditadura militar no Brasil”. Versão revista e ampliada de sua dissertação, sendo a primeira obra a ser escrita na área da história, sendo mais um dos clássicos sobre a temática. Comparativamente, Colling faz um trabalho mais aprofundado e específico que Ridenti e com maior aporte da história que Ferreira, sendo que a partir de entrevistas e cruzamento de fontes tece algumas considerações sobre a presença das mulheres na resistência à ditadura. Como destaca:

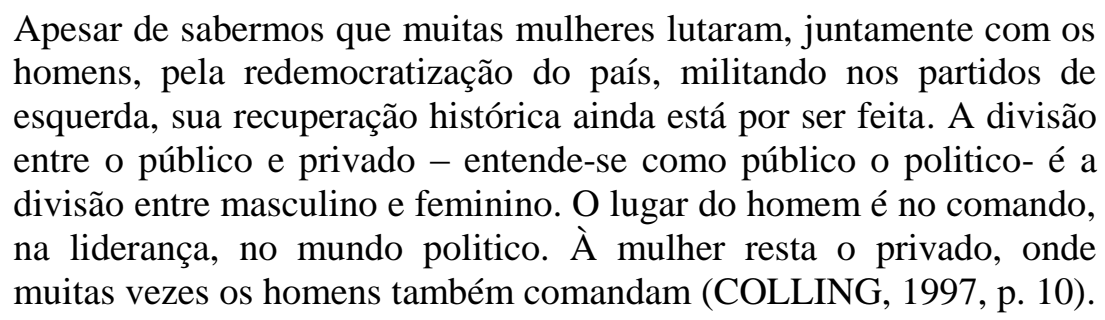

No que tange a resistência das mulheres no período, segundo a referida autora, esta se dava não apenas no campo político, mas também cultural, levando em consideração à forma na qual as mulheres estavam inseridas naquela sociedade. Logo, apesar de propor uma resistência, além uma revolução democrática, no campo cultural os movimentos de esquerda continuavam a reproduzir um olhar diferenciado à mulher. Este fato pode ser entendido a partir dos próprios movimentos de esquerda, que traziam consigo a perspectiva moral e social daquela sociedade para dentro de sua organização. Sendo assim, a visão romântica de uma esquerda que lutava por igualdade e lutas sociais precisa ser vista com ressalvas, haja vista a influência que o período histórico tinha sobre os movimentos e relações sociais, posto que cada movimento ou grupo é fruto de seu tempo (COLLING, 1997).

Um dos pontos que tem destaque na obra de Colling é a forma pela qual as mulheres eram vistas no período, a mulher subversiva, por exemplo, como eram consideradas as que se envolviam em movimentos de esquerda, "era um sujeito desviante, acompanhando homens ou à procura de homem" (COLLING, 1997, p. 111). Os editoriais da imprensa e dos documentos produzidos pelos órgãos de repressão Fronteiras: Revista de História | Dourados, MS |v. 20 | n. 36 | p. 177-199 | Jul. / Dez. 2018 
utilizavam com frequência adjetivos pejorativos para se referirem as mulheres reforçando o seu papel estando à vida privada. Esse fator é de extrema importância para percebermos as implicações da presença das mulheres na política dos anos 60 , algo que interferiu não apenas no âmbito familiar, mas na relação entre o privado e o público, o mundo doméstico e a política.

Em 1998, o jornalista Luís Maklouf Carvalho lança a obra "Mulheres que foram à luta armada", onde, a partir de entrevistas são relatadas diferentes resistências de mulheres no período e às práticas de tortura as quais foram submetidas. A partir dos testemunhos de mulheres que ousaram lutar no período e documentos da época, Carvalho busca debater a presença das mulheres dentro dos movimentos de esquerda e suas heterogenias dentro da luta política. Assim, configura-se também como uma das referências importantes para a análise do período ditatorial brasileiro e sua relação com as mulheres, completando o "boom" acadêmico sobre o tema na década de 90.

\section{OBRAS PÓS ANOS 2000}

No século XXI, houve um grande avanço em publicações referentes a participação das mulheres na resistência a ditadura, a exemplo de teses e dissertações que deram origens a livros. Destacam-se as obras, Mulheres e militância-Encontros e confrontos durante a ditadura militar das psicólogas sociais Ingrid GianardoliNascimento, Zeidi Trindade e Maria Santos (2012); Sem liberdade eu não vivo mulheres que não se calaram na ditadura das jornalistas Laura Bordin e Suelen Lorianny (2013) e A aventura de contar-se: feminismos, escrita se si e invenções da subjetividade" da historiadora Margareth Rago (2013).

O livro "Mulheres e militância - Encontros e confrontos durante a ditadura militar", traz um olhar diferenciado sobre o tema, pois, a partir da psicologia, propõe apresentar e discutir a construção social de nove mulheres do estado do Espírito Santo na resistência à ditadura a partir de suas memórias. Como destacam as autoras, a adesão da juventude ao movimento estudantil é uma das principais características que compõe o perfil das mulheres por elas estudadas, algo que adentra o perfil de muitas outras militantes. No que concerne à pesquisa realizada, as autoras destacam que na luta 
armada ou na oposição à ditadura militar as mulheres enfrentavam riscos que iam desde a negação da identificação de feminilidade à sua negação sentimental. Tal ponto, Colling (1997), problematiza, ao demonstrar que algumas mulheres pertencentes a movimentos de esquerda deixavam a sexualidade e suas paixões de lado, negando sentimentos, deixando de expressar seu lado amoroso por conta da militância.

Ingrid Gianardoli- Nascimento, Zeidi Trindade e Maria Santos (2012) destacam que muitas mulheres viam a morte como algo possível na militância, considerando o óbito também como uma espécie de resistência em determinados momentos. Ou seja, para muitos militantes, após cansativos interrogatórios, banhados de tortura, a preferencia pela morte se dava contra a opção de delatar seus companheiros.

Outro aspecto importante é a heterogenia da participação das mulheres e de seus posicionamentos políticos, uma vez que algumas de determinados partidos e organizações teciam críticas a outras de partidos diferentes, fossem por suas ações ou posturas ideológicas. Assim, como exemplo, mulheres ainda que engajadas, mas religiosas eram vistas como "caretas" por outras, algo importante para perceber que não só os movimentos de esquerda eram heterogêneos, mas seus agentes sociais, como as mulheres também o eram.

Discutindo não apenas questões históricas, psicológicas e de identidade, os relatos apresentados pelas autoras permitem reflexões do quanto o campo da História precisa estar atento à interdisciplinaridade como ferramenta, observando que o campo historiográfico não da conta de explicar a tudo.

No ano de 2013, as jornalistas Laura Bordin e Suelen Lorianny publicaram a obra "Sem liberdade eu não vivo - mulheres que não se calaram na ditadura". Neste estudo as autoras fazem uma série de entrevistas, com seis mulheres que militaram no período, especificamente no estado do Paraná. No complemento da obra, trazem três relatos de mulheres que no período estavam na condição de filhas e irmãs de mulheres em militância política. Importante destacar que mesmo não se tratando de um trabalho historiográfico, pois as entrevistas não são problematizadas nem cruzadas com outras fontes primárias, tal obra traz elementos importantes para o debate a que o artigo se propõe. Contudo, ressalvamos, a necessidade das devidas problematizações e críticas 
em torno da memória dos anos de chumbo, percebendo-se, inclusive, o quanto o presente traz influencias na construção da narrativa sobre o passado (SARLO, 2007).

Também em 2013, a historiadora Margareth Rago lançou a obra A aventura de contar-se: feminismos, escrita de si e invenções da subjetividade. Fazendo uso de relatos memorialísticos de sete mulheres, tece importantes enfoques no âmbito da escrita de si e da subjetividade, tendo Foucault como seu principal teórico. Realizando considerações importantes no âmbito da reconstrução memorialística, Rago também utiliza das rupturas, dos silêncios, situações vividas, além do feminismo encontrado em muitas como ferramentas importantes para observar como impactam na vida das mulheres apresentadas na obra, bem como suas próprias reinvenções.

Após um árduo trabalho no levantamento de tais obras, observamos o quanto a heterogeneidade das abordagens permite um olhar diferenciado, tanto pela vivência individual apresentada, bem como pelas particularidades de estados, regiões e municípios brasileiros. Assim, acredita-se que à medida que trabalhos como estes vão sendo apresentados, novas ideias vão surgindo e a bibliografia sobre o tema crescendo, algo que também pretendemos contribuir.

\section{TESES E DISSERTAÇÕES}

No tocante as teses e dissertações em torno da resistência feminina à ditadura militar, destaca-se seu crescimento e as diferentes abordagens possíveis. Ao realizar um breve levantamento, apresentamos alguns trabalhos, como os de Glória Gabriel (2005), Olívia Joffily (2005), Mônica Cappelle (2006), Natalia Bastos (2007) Ary Cavalcanti Junior (2016) Além disso, nesta pesquisa foi possível perceber que a Universidade de Campinas, a Pontifícia Universidade Católica de São Paulo, e as Universidades Federais de Santa Catarina, Uberlândia e Grande Dourados apresentam estudos avançados no campo da história de gênero.

No mapeamento de teses e dissertações, verificamos ainda a existência de uma intensa produção de trabalhos sobre mulheres na ditadura. Contudo, por uma questão seletiva, voltada para trabalhos que se distingam, em prol de uma apresentação variada de abordagens privilegiamos alguns estudos. Em sentido cronológico de suas defesas, o 
primeiro estudo é a dissertação de Karen Silva Debértolis (2002), Brasil mulher: Joana Lopes e a imprensa alternativa feminista, no qual a autora faz reflexões importantes sobre a resistência de Joana Lopes, importante escritora e cineasta, militante do período, a partir de seus escritos, atos e matérias no jornal Brasil mulher por ela fundado em Londrina, no Paraná.

Fazendo uso da história oral, Debértolis (2002) realizou entrevistas com Joana Lopes entre os anos de 1999 e 2001, a qual durante sua vida militante passou a ser perseguida e sofrer com a repressão, principalmente ao ingressar na Universidade Estadual de Londrina em 1971. Em entrevista concedida em 2001, e apresentada por Debértolis, Joana Lopes afirmou que não fez parte de nenhum partido ou organização de esquerda, algo que fortalece a visão de que a resistência à ditadura não significava ter filiação partidária ou ligação direta com organizações políticas.

Em 2005, Olívia Joffily, defende a tese "Esperança equilibrista: Resistência feminina à ditadura militar no Brasil (1964-1985)" realizando treze entrevistas com mulheres que apoiaram e participaram na luta pela resistência à ditadura militar, esta "remonta" a trajetória das mulheres. De excelente escrita, Joffily contribui para os estudos sobre a mulher na ditadura militar trazendo o amplo cenário de vida das pessoas que entrevista, passando desde a experiência de guerrilhas, partidos clandestinos a movimentos sociais. Além disso, tece reflexões importantes no trato da relação mulherresistência e ditadura, ao pontuar o quanto é ampla a palavra "resistência", podendo esta ser aplicada a diversos contextos.

Em sua pesquisa, Joffily traz uma reflexão importante quanto à visão romântica em torno da esquerda brasileira e das mulheres na militância, bem como a formação social das mulheres envolvidas com as esquerdas e suas heterogeneidades, algo que se encontra em trabalhos anteriores, se solidificando como uma característica bem comum.

Em 2007, Natália Bastos em sua dissertação Elas por elas: tradição de uma trajetória de mulheres de esquerda no Brasil - anos 1960 - 1980 buscou investigar a trajetória política de mulheres que se envolveram no projeto das esquerdas e seu ideário revolucionário. Trazendo uma excelente reflexão em torno da valorização da democracia e da presença das mulheres na sociedade, esta autora menciona que, ainda que os partidos de esquerda debatessem internamente melhores formas de militância 
As mulheres brasileiras na ditadura civil-militar: avanços e abordagens em quase quatro décadas de resistência Ary Albuquerque Cavalcanti Junior

para seu grupo, no âmbito das discussões culturais, como a liberdade sexual e a igualdade de gênero não ocorriam.

$\mathrm{Na}$ vida cotidiana das militantes, o debate feminista transformou relacionamentos, colocou em xeque posições e conceitos políticos. Mas, no campo público, reproduziu com frequência posicionamentos, valores e ações dos tempos da militância armada. O mundo ainda continuava dividido entre opressores e oprimidos. A burguesia oprimia o proletariado, o homem oprimia a mulher. Rupturas e continuidades. Heranças de uma cultura politica. Permanências tão caras às esquerdas dos anos 1960 (BASTOS, 2007, p. 131).

Em 2011, Júlia Insuela (2011) em sua dissertação Visões das mulheres na luta armada: repressão, imprensa e (auto) biografias (Brasil 1968/ 1971) deu ênfase às ações de mulheres na luta armada entre os anos que destaca, e faz uma analise sobre a cobertura que a imprensa e os órgãos de repressão teciam sobre as mulheres.

Um dos pontos que merece que Insuela (2011) chama atenção é a influência que os movimentos de maio de $1968^{4}$ trouxeram para o mundo, inclusive para o Brasil e sua militância. Segundo esta estudiosa, mesmo com a sanção do Ato Institucional $\mathrm{n}^{\circ} 5 \mathrm{em}$ 13 de dezembro de1968 pelo governo ditatorial, os sentimentos românticos e de mudança continuaram com intensidade, em meio aos movimentos estudantis e sociais. Além disso, Insuela destaca a relação entre a rebeldia e a juventude, algo muitas vezes pensado como interligado, ponto este questionado pela pesquisadora. Essa inclusive é uma questão bastante peculiar, pois erroneamente a rebeldia costuma ser associada á juventude, o que precisa ser relativizado, posto que nem todos os jovens eram rebeldes ou faziam qualquer tipo de oposição ao governo, a exemplo do Comando de Caça aos

\footnotetext{
${ }^{4}$ O movimento de maio de 1968 na França se deu a partir das manifestações estudantis e de trabalhadores em Paris. Dentre as lutas dos estudantes estavam a reforma educacional, sendo duramente reprimidos. Além de trazer as discussões e posicionamentos políticos ao mundo, tal movimento intensificou as revoluções de comportamento e consequentemente a presença da juventude na militância politica tanto internacional quanto nacional. Slogans como "é proibido proibir" e "prazer sem restrições" receberam muito destaque, algo que encontramos facilmente no Brasil. Ver: THIOLLENT, Michel. Maio de 1968 em Paris: testemunho de um estudante. Tempo Social; Rev. Sociói. USR S. Paulo, 10(2): 63-100, outubro de 1998. Disponível em: http://www.scielo.br/pdf/ts/v10n2/v10n2a06 Acesso em 28/06/2016 às $21: 21$
}

Fronteiras: Revista de História | Dourados, MS |v. 20 | n. 36 |p. 177-199 | Jul. / Dez. 2018 
Comunistas $(\mathrm{CCC})^{5}$, grupo formado dentro da Faculdade Mackenzie em São Paulo liderado por jovens.

Em 2013, Jaíza Cruz, diferente de Insuela (2011,) faz uma análise das militantes e suas relações com a maternidade durante a ditadura. Pontua-se que muitas mulheres já ingressaram na vida política em período de gestação, enquanto outras engravidaram e gestaram seus filhos durante a luta contra o regime autoritário. Nessa perspectiva, Cruz entrevista quatro mulheres que estiveram grávidas, deram a luz ou interromperam a gravidez durante a militância. Apesar de ser um trabalho de psicologia e apresentar discussões específicas da área, a autora traz abordagens inovadoras, bem como visões e reflexões sobre as mulheres e sua relação com a ditadura, algo de grande contribuição para a pesquisa histórica.

Segundo Cruz (2013, p. 120), “ter que escolher entre a militância e o exercício da maternidade, sinaliza que a mulher que militava estava no lugar impróprio, pois o lugar da mãe era no seio da família, e não nas ruas (...)". Assim, a sociedade da época com seus códigos morais contribuía para o aumento das críticas e dos olhares negativos em relação às mulheres grávidas que partiram para a luta politica. No entanto, o fato de estarem grávidas não as eximia de sofrerem torturas das mais cruéis, deixando sequelas ate os dias atuais.

Algo que merece destaque, bastante relatado por mulheres militantes foram às torturas permanentes, principalmente para as que tiveram a tortura da violação, o estupro, como marca maior. Por consequência, muitas dessas gestaram filhos de seus próprios torturadores, gerando desde a repulsa a criança a problemas como depressão antes e pós- parto (CRUZ, 2013). Em 2014, a Comissão da Verdade de São Paulo lançou a obra Infância roubada: Crianças atingidas pela ditadura militar no Brasil, que contando com 40 depoimentos de pessoas que vivenciaram o período da ditadura entre seus quatro e doze anos de idade, relatam os horrores pelos quais passaram ao verem seus pais serem torturados, sofrendo traumas irreversíveis.

\footnotetext{
${ }^{5}$ Fundado em 1963 pelo policial civil e estudante de Direito Raul de Lima, o "Raul Careca", o CCC foi uma organização paramilitar anticomunista brasileira cuja composição se dava, sobretudo, por estudantes das Universidades Makenzie e outras particulares do período.
} 
Em 2015, Débora Ataíde Reis (2015) com a dissertação Memória(s) militante(s): narrativas Autobiográficas e imagens de resistência em Derlei Catarina de Luca (19661973) faz uma análise da vida da militante destacada. Tecendo uma abordagem riquíssima no trato com suas fontes e partir de seus cruzamentos apresenta os anseios da militante, bem como os caminhos que a levaram a praticar ações contra o regime. Como foco, Reis destaca o período de militância de Derlei entre os anos de 1966 e 1973, quando a mesma atuou na Ação Popular (AP).

Fazendo uso de fontes autobiográficas, Reis remonta as ações da militante referida, com o cuidado de apresentar seus primeiros passos na AP relacionando-os com o tempo histórico e seus diferentes contextos, discutindo conceitos e noções, como geração, feminilidade e memória. Além disso, assim como Cruz (2013), Reis (2015) destaca a questão da maternidade como um fator diferencial para a vida de muitas militantes durante o regime. Nessa perspectiva, a maternidade também aparece nas memórias e na autobiografia de Derlei Catarina de Lucca, o que remonta as inúmeras situações a que estavam suscetíveis às militantes mulheres.

Em 2015, Carla Cristina Conradi defendeu a tese Memórias do sótão”: vozes de mulheres na militância política contra a ditadura no Paraná (1964-1985), trazendo a partir da narrativa autobiográfica de quatorze mulheres a luta e a resistência contra a ditadura. Nesta pesquisa, Conradi apresenta como tais mulheres romperam padrões estabelecidos pela sociedade e escolheram seus projetos de vida. Como em outras pesquisas, Conradi (2015) trabalha a noção de política voltada à presença da mulher na história, onde a partir das relações de poder colocaram a diferença sexual como principal medida de diferenciação. Além disso, destaca a relação direta entre a construção da memória e a subjetividade, e ao apresentar tais reconstruções memorialísticas, destaca as confluências e divergências que cercavam as mulheres no período.

Após destacar tais pesquisas é possível refletir sobre as diferentes perspectivas e ações das mulheres durante o regime militar brasileiro em seus estados de atuação. Logo, a cada ano, surge novas teses e dissertações que buscam apresentar e colocar as mulheres no centro dos debates políticos que ocorreram no país. Além disso, destacamos, também, o surgimento de trabalhos com a história cultural, das minorias e 
As mulheres brasileiras na ditadura civil-militar: avanços e abordagens em quase quatro décadas de resistência Ary Albuquerque Cavalcanti Junior

de gênero, algo que juntamente com o papel político de algumas professoras e Programas de pós-graduação, e a luta de muitas militantes pelo direito à memória e por reparação contribuíram no desenvolvimento de pesquisas sobre o tema. Nessa perspectiva importante ressalvar os escritos de pesquisadoras como Joana Pedro e Cristina Wolff, as quais contribuem de forma significativa não apenas no âmbito das reflexões acerca das mulheres no período, mas também sobre gênero e suas possibilidades de análise ${ }^{6}$.

\section{A LITERATURA QUE REMEMORA OS ANOS SOMBRIOS}

$\mathrm{Na}$ proposição de releituras de obras literais sobre o período, privilegiamos as poucas que têm o intuito de apresentar a participação das mulheres na resistência à ditadura civil-militar. Para isso, nos atentamos à vida e obra do (a) escritor (a), bem como ao público para quem o autor (a) escreveu. Ademais, as obras são entendidas aqui enquanto produtos da subjetividade e da liberdade poética.

Nessa perspectiva, apresentamos as obras A revolta das vísceras: Uma visão feminina da luta armada no Brasil - uma história de paixão e morte de Mariluce Moura (1982) e Uma história para Érica de Jô Moraes (2002). A primeira trata de um romance que tem como fundo o período ditatorial brasileiro e a visão feminina da luta armada e a segunda um romance que remonta a vida da autora entre a clandestinidade e suas várias identidades.

Na obra de Moura (1982), é importante ressalvar que esta foi presa juntamente com seu marido Gildo Lacerda (ex-militante da Ação popular) em 1973 e ao longo de seu romance a presença de rememorações suas estão intrínsecas nos personagens, algo perceptível, principalmente através de Clara, personagem principal da trama. Como afirma Insuela (2011) o olhar da obra de Moura (1982) é centrado na participação feminina, sendo esse um dos pontos que chama atenção.

\footnotetext{
${ }^{6}$ Em 2010 as referidas autoras lançaram a obra Gênero, feminismos e ditaduras no Cone Sul a qual traz inúmeros artigos produzidos com a temática, sendo uma leitura importante, pois, permite uma reflexão a partir de casos do Cone Sul. Na obra há contribuições quanto à ditadura na Argentina, Paraguaia, Uruguai além de depoimentos, algo que nos permite tecer uma análise proximidade e afastamentos quanto à ditadura e as questões de gênero e feminismo entre o Brasil e os demais países.
}

Fronteiras: Revista de História | Dourados, MS |v. 20 | n. 36 | p. 177-199 | Jul. / Dez. 2018 
Apesar de uma obra literal, Mariluce Moura problematiza as funções políticas sempre atribuídas aos homens, bem como a distância entre feminilidade e militância, o que forçaria as mulheres a se masculinizarem e/ ou se colocarem como assexuadas, desprovidas de vaidade, como destaca Colling (1997). Em uma das passagens do romance Moura descreve:

Clara se imaginava vestindo um vestido desbotado, o rosto lavado sem nenhuma pintura, o cabelo amarrado, desajeitado... mas a clandestinidade é uma barra muito pesada... heroína romântica, ao contrário da que se imaginara na infância, não a princesa belíssima, mas a mulher feia, sem nenhum encanto, uma ponta de tristeza se insinuava e ela a afastava com vigor, entregue ao seu destino (MOURA, 1982, p. 44).

É importante atentar para a reflexão de Moura (1982) a partir das palavras de sua personagem Clara quanto à vida na clandestinidade, que apresentava pontos de tristeza e abdicação a determinadas ações e sonhos. Dessa forma, podemos perceber que abdicar de ser feminina, ser vaidosa, de preocupar-se com a beleza são pontos que não impediriam o envolvimento das mulheres na atividade politica, reprimindo sua libertação individual. Contudo, naquela sociedade em que viviam, as mulheres eram discriminadas não só socialmente, mas dentro dos próprios partidos e organizações de luta armada, o que as forçava muitas vezes a adaptarem-se ao universo masculino. Nessa perspectiva, podemos observar a passagem da personagem Clara, como uma espécie de abandono de suas características femininas, tornando-se "masculinizada" trazendo um conformismo infeliz para a personagem, fato esse explorado anos mais tarde nos trabalhos de Ferreira (1996); Colling (1997) e Gianardolli-Nascimento (2012) como característica de muitas ex-militantes. Ainda, como destaca Ridenti (2000), muitos homens confundiam libertação sexual feminina com possibilidade de "pegação", o que fazia com que as mulheres fossem assediadas nas organizações. Talvez para evitar isso e serem respeitadas pela atuação e inteligência, essas mulheres acabaram se masculinizando para serem tratadas de uma forma mais igual por seus companheiros de luta.

Trazendo outra importante reflexão do período através de sua obra, Moura (1982) problematiza a heterogeneidade das mulheres dentro da sociedade da época, bem como os tabus em torno da sexualidade. Em duas passagens do livro a autora deixa essa Fronteiras: Revista de História | Dourados, MS | v. 20 | n. 36 | p. 177-199 | Jul. / Dez. 2018 
As mulheres brasileiras na ditadura civil-militar: avanços e abordagens em quase quatro décadas de resistência Ary Albuquerque Cavalcanti Junior

questão visível, como por exemplo, no diálogo entre as duas personagens, Clara e Maria:

Falaram um dia de relacionamento afetivo... se relacionar com alguém que tivesse a mesma perspectiva de vida... Maria falou de se relacionar sexualmente antes do casamento. Sem casar? O susto de Clara e a ideia logo admitida intelectualmente. É Clara, o casamento legal, se houver, é somente uma concessão à família. Se o relacionamento for bom, se as ideias forem as mesmas, as mesmas perspectivas, tem mais é que trepar! (MOURA, 1982, p. 44-45)

A partir do diálogo acima, os anseios, dúvidas e padrões culturais que permeavam as mulheres naquele período é destacado a partir do imaginário da autora. Importante pontuar que o ato de ter ou não relações sexuais antes do casamento era algo que estava relacionado à sociedade e não apenas aos movimentos de esquerda, haja vista que muitas mulheres já haviam rompido o obstáculo de discutir a presença e a autonomia das mulheres na sociedade. Além do mais, a intensidade da vida na clandestinidade causou bastante impacto nas ações dos envolvidos, em sua maioria jovens, distantes dos padrões estabelecidos e levando em consideração inclusive morrerem ou serem presos a qualquer momento.

Em sua obra, Moura permite a partir das reflexões da personagem Clara, observar questões que marcaram as mulheres durante a militância nos tempos da ditadura. Ainda que o uso da literatura sofra questionamentos por parte de historiadores, a mesma apresenta características importantes para refletir sobre a influência da revolução sexual e comportamental que marcaria essa geração dos anos 60 (RIDENTI, 2000).

Por fim, observamos "Uma história para Érica - fragmentos da vida sob a ditadura militar", escrita de forma independente por Jô Moraes (2002) ${ }^{7}$. Obra literalmemorialística, a mesma relata o período em que viveu na clandestinidade e militou contra a ditadura. No decorrer de suas páginas a autora demonstra as particularidades do ser mulher no período ditatorial, além da dificuldade em viver na clandestinidade. Para isso, faz uma homenagem a jovem atriz chamada Érica, que no período anterior à

\footnotetext{
${ }^{7}$ Nascida em João Pessoa, Jô Moraes até hoje se considera uma militante comunista, algo expressado na contra capa de sua obra. Perseguida pela ditadura viveu na clandestinidade até fixar-se em Minas Gerais na década de 70. Atualmente é Deputada Federal pelo PC do B de Minas Gerais.
} 
confecção de sua obra, encantara Jô Moraes por conta de seu idealismo e paixão pelo teatro, o que supostamente a fez lembrar-se dos seus anos de militância.

A partir desta obra, Jô Moraes faz um trabalho interessante do ponto de vista bibliográfico, apresentando documentos do período, algo que dá maior ênfase a sua luta política, acreditamos que outras editoras poderiam reeditar ou publicar sua obra, porém, não a fizeram. Contudo, apesar de possuir poucas páginas e ser um trabalho autoral Moraes apresenta uma visão bem pessoal do que foi o período militar sob a ótica das mulheres, bem como tece sua visão sobre a vida política.

Um ponto em comum nestas obras literais é a presença das mulheres no seio da participação política e dos anseios sociais. Em todas se percebe as relações de gênero direta ou indiretamente, onde a vivência dentro dos movimentos de esquerda e das práticas de tortura deixam indícios da diferenciação de cargos nos partidos e da própria sociedade da época, algo confirmado em trabalhos anteriormente mencionados.

\section{CONCLUSÃO}

Após os trabalhos analisados, é possível perceber que há uma quantidade significativa de mulheres que tiveram uma vida ligada à política e a movimentos sociais durante o período ditatorial brasileiro. Muitas dessas partiram para a militância política tendo que lidar com olhares diferenciados tanto dos órgãos de repressão, bem como de dentro dos próprios movimentos de oposição, sem esquecer obviamente do olhar social. Dessa forma, fica nítida que a participação das mulheres, bem como suas militâncias durante a ditadura apresentam aspectos importantes para se analisar não apenas questões voltadas à política, mas também a fatores culturais que condicionavam o período.

A partir do exposto, acredita-se nas inúmeras contribuições que as obras mencionadas trazem não apenas para os debates acerca do tema, mas para as inúmeras pesquisas que se debrucem sobre as mulheres e as relações de gênero. No que se refere ao período, não devemos esquecer que a atual conjuntura do país e as ondas de pedidos ao retorno da ditadura, fazem desses trabalhos porta vozes de uma resistência contínua. E longe de abarcar todas as obras que debatam o tema, a esperança que este trabalho 
esteja obsoleto em termos quantitativos se torna um desejo, prevendo uma quantidade ainda maior de estudos.

\section{REFERÊNCIAS}

BASTOS, Natália. Elas por elas: trajetória de uma geração de mulheres de esquerda no Brasil - anos 1960-1980. Dissertação de Mestrado Niterói: UFF, 2007.

BORDIN, Laura Beal; LORIANNY, Suelen. Sem liberdade, eu não vivo - Mulheres que não se calaram na ditadura. Curitiba: Compactos, 2013.

CAPPELLE, Mônica. O trabalho feminino no policiamento operacional: subjetividade, relações de poder e gênero na oitava região da Polícia Militar de Minas Gerais. Tese de doutorado. UFMG, 2006

CARVALHO, L.M. Mulheres que foram a luta armada. São Paulo: Globo, 1998.

CAVALCANTI JÚNIOR, Ary Albuquerque. "Para não dizer que não falei das flores": Memórias de mulheres na resistência à ditadura civil-militar (1964-1985). Dissertação (mestrado), Universidade do Estado da Bahia - UNEB, Santo Antônio de Jesus, BA, 2016.

CAVALCANTI, Celso Uchôa; RAMOS, Jovelino. Memórias do exílio- 1964-19??. Rio de Janeiro: Paz e Terra, 1980.

COLLING, Ana Maria. A resistência da mulher à ditadura militar no Brasil. Rio de Janeiro: Rosa dos Tempos, 1997.

CONRADI, Carla Cristina N. "Memórias do sótão": vozes de mulheres na militância política contra a ditadura no Paraná (1964-1985). (Tese) Programa de pós-graduação em História. Universidade Federal do Paraná, 2015

DEBÉRTOLIS, Karen Silvia. Brasil mulher: Joana Lopes e a imprensa alternativa feminista. Dissertação de Mestrado. Universidade Federal do Rio Grande do Sul. Faculdade de Biblioteconomia e Comunicação. Programa de Pós-Graduação em Comunicação e Informação, 2002

FERREIRA, Elizabeth F. Xavier. Mulheres, militância e memória. Rio de Janeiro: Fundação Getúlio Vargas, 1996

GABRIEL, Glória Cristina. A recepção das músicas de Chico Buarque na ditadura militar: o universo feminino não cála, fála! Dissertação de Mestrado, PUC/RS: 2005. 
GIANORDOLI-NASCIMENTO, Ingrid Faria; TRINDADE, Zeidi Araujo; SANTOS, Maria de Fátima de Souza. Mulheres e militância: encontros e confrontos durante a ditadura militar. Belo Horizonte: Ed. UFMG, 2012.

HALBWACHS, Maurice. A Memória Coletiva. São Paulo: Vértice, 1990.

PEDRO, Joana Maria; WOLFF, Cristina Scheibe. Gênero, feminismos e ditaduras no Cone Sul. Florianópolis: Ed. Mulheres, 2010.

JOFFILY, Olívia Rangel. Esperança equilibrista. Resistência feminina á ditadura militar no Brasil (1964-1985). Tese de doutorado. PUC-SP: 2005.

MORAIS, Jô. Uma história para Érica. Belo Horizonte: Lutador. 2002

MOURA, Mariluce. A revolta das Vísceras. Rio de Janeiro: Codreci, 1982

RAGO, Margareth. A aventura de contar-se: feminismos, escrita de si e invenções da subjetividade. Campinas, SP: Editora da Unicamp, 2013

REIS, Débora Ataíde. Memória(s) militante(s): narrativas Autobiográficas e imagens de resistência em Derlei Catarina de Luca (1966-1973). (Dissertação) Programa de PósGraduação em História Social. Universidade Federal da Bahia. 2015

RIDENTI, Marcelo. S. As mulheres na política brasileira: os anos de chumbo. Tempo Social: Revista de Sociologia da USP, São Paulo, v.2, n.2, p. 113-128, 1990.

O fantasma da revolução brasileira. São Paulo: Unesp, 1993.

Em busca do povo brasileiro: artistas da revolução, do CPC à era da TV. Rio de Janeiro /São Paulo, Editora Record, 2000

SANTANA, Ediane Lopes de. Campanha de desestabilização de Jango: as 'donas' saem às ruas! In: ZACHARIADHES, Grimaldi (orgs). Ditadura militar na Bahia: novos olhares, novos objetivos, novos horizontes. vol. 1. Salvador: EDUFBA, 2009 p. 28

SARLO, Beatriz. Tempo passado. São Paulo: Companhia das Letras, 2007.

VIANA, Gilney Amorim. Glória: Mãe de preso político. São Paulo: Paz e Terra, 2000.

Recebido em: 15/04/2018

Aprovado em: 16/08/2018 